\title{
Cipango
}

Cipango Cahiers d'études japonaises

$17 \mid 2010$

La péninsule retrouvée

\section{Étude de l'organisation des poèmes des quatre saisons et d'amour dans le Kokin waka-shû, première anthologie impériale de poésie japonaise}

\section{Sébastien Faber}

\section{OpenEdition}

Journals

Édition électronique

URL : https://journals.openedition.org/cipango/1499

DOI : 10.4000/cipango.1499

ISSN : 2260-7706

Éditeur

INALCO

Édition imprimée

Date de publication : 30 juin 2010

Pagination : 301-302

ISBN : 978-2-85831-195-8

ISSN : 1164-5857

Référence électronique

Sébastien Faber, «Étude de l'organisation des poèmes des quatre saisons et d'amour dans le Kokin waka-shû, première anthologie impériale de poésie japonaise », Cipango [En ligne], 17| 2010, mis en ligne le 21 novembre 2012, consulté le 30 juin 2021. URL : http://journals.openedition.org/cipango/ 1499 ; DOI : https://doi.org/10.4000/cipango.1499

Ce document a été généré automatiquement le 30 juin 2021.

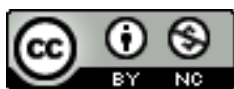

Cipango est mis à disposition selon les termes de la Licence Creative Commons Attribution - Pas d'Utilisation Commerciale 4.0 International. 


\title{
Étude de l'organisation des poèmes des quatre saisons et d'amour dans le Kokin waka-shû, première anthologie impériale de poésie japonaise
}

\author{
Sébastien Faber
}

\section{RÉFÉRENCE}

Sébastien Faber, Étude de l'organisation des poèmes des quatre saisons et d'amour dans le Kokin waka-shû, première anthologie impériale de poésie japonaise. Mémoire de Master 2 soutenu par Sébastien Faber, sous la direction de Terada Sumie, INALCO, 2009.

1 Compilé sur ordre impérial au début $\mathrm{du} \mathrm{x}^{\mathrm{e}}$ siècle, le Kokin waka-shû est la première anthologie officielle de poésie japonaise. Ce statut particulier lui confère une place prépondérante et un prestige unique dans la littérature japonaise, relevant à la fois de la qualité des pièces qui y sont compilées, mais également de la manière dont celles-ci sont agencées.

Dans ce mémoire, nous avons cherché à analyser l'organisation des poèmes d'amour de l'anthologie, après avoir observé celle des poèmes des quatre saisons dans un précédent travail. Ces deux ensembles constituent les parties les plus importantes du Kokin wakashū.

De prime abord, les poèmes d'amour semblent, à l'instar de ceux des saisons, suivre un axe temporel pour décrire une relation de son commencement jusqu'à sa fin. Cependant, il est clair que l'organisation des poèmes ne se résume pas à cet unique vecteur. Nous sommes en présence de différents facteurs qui se superposent avec des degrés d'importance variables au long des cinq livres de poèmes d'amour. 
4 L'importance du vecteur temps, qui symbolise la progression de la relation, varie en fonction des livres. Le passage du temps est prépondérant dans les phases où les amants se rencontrent (livres III \& IV), il est par contre d'une importance beaucoup plus relative dans les poèmes évoquant les différents sentiments de leurs auteurs (livres I, II $\& \mathrm{v})$. Ainsi, dans les livres où l'évolution de la relation amoureuse guide moins strictement l'organisation des pièces, certains poèmes sont rassemblés en fonction des images qu'ils emploient, sans lien apparent avec une évolution temporelle de la relation.

5 L'organisation des poèmes en fonction de l'époque à laquelle appartiennent leurs auteurs est également essentielle. Les œuvres des auteurs considérés comme les plus anciens ont été compilées dans le premier livre, et celles des auteurs plus récents dans le deuxième. Cet agencement représente une opposition entre ancien et moderne. Il en va de même, à une plus grande échelle, entre les deux premiers livres dont l'organisation chronologique des poèmes reprend une méthode de classement visible dans le Man.yō-shū ; et les deux suivants dont les poèmes sont organisés de manière à suivre l'évolution de la relation amoureuse, ce qui constitue une nouvelle méthode de compilation.

6 Les ensembles que constituent les livres des saisons et ceux d'amour cherchent tous deux à représenter le déroulement d'une progression modèle dans son inexorabilité pathétique. Cette représentation se fait à travers une succession de groupes de poèmes qui figurent les différentes phases d'un long processus déformé par le prisme de la convention poétique. Les livres des poèmes d'amour semblent clairement faire écho à ceux des saisons, et ces deux ensembles constituent les points centraux d'une compilation qui cherche à vanter les fastes de la poésie japonaise face à la nature d'une part et sa capacité à retranscrire les sentiments humains de l'autre.

7 Cependant, ces deux ensembles de poèmes diffèrent au niveau de leur organisation. Le premier incarne une forme nouvelle de compilation, se basant de façon primordiale sur une évolution temporelle cyclique. Le second suit avec moins de rigueur une évolution linéaire et représente un lien avec des époques et des formes de compilation plus anciennes. Nous pouvons également trouver parmi les poèmes d'amour des pièces regroupées par paires: qu'il s'agisse de correspondances réelles ou de dialogues fabriqués, ce type de regroupement est lié à la nature même du propos et ne se rencontre pas dans les livres des saisons.

8 Au cours de cette étude de l'organisation des poèmes d'amour, notre attention s'est particulièrement focalisée sur leur cinquième livre. Ce dernier livre nous a en effet semblé avoir un statut particulier, hybride, sa structure ne ressemblant ni aux livres mettant en avant la chronologie des auteurs, ni à ceux suivant plus précisément l'évolution de la relation amoureuse. De plus, il contient dans des proportions non négligeables des auteurs absents des autres livres de poèmes d'amour. Est-il possible d'imaginer que les principes directeurs de la compilation aient été modifiés avant la compilation du cinquième livre ? Celui-ci permet néanmoins à l'ensemble des poèmes d'amour d'égaler en nombre de pièces celui des saisons et de créer une structure globale du recueil qui servira de modèle à toutes les anthologies impériales japonaises. 